\title{
Some Remarks on Impact of Mining Based on an Example of Building Deformation and Damage Caused by Mining in Conditions of Upper Silesian Coal Basin
}

\author{
Piotr STRZAłKOWSKI ${ }^{1}$
}

\begin{abstract}
An intense mining exploitation has been conducted below a highly urbanised area of Upper Silesian Coal Basin for over 100 years. Its influence on the surface and buildings located in the area constituted a subject of many studies, the result of which helped in creating methods allowing to predict deformations and assessing the extent of their impact on buildings. However, there is a number of issues linked with assessment of mining influence on terrain surface deformation, reliable analyses should be carried out individually in respect to particular mining and geological conditions. All calculation results concerning deformations of the mining area, as well as rock mass tremors' occurrence, can be verified based on measurements results. This paper presents an analysis of exploitation's impact on a selected structure. Conclusions about the manner of performing the assessment of exploitation's impact on buildings were based on obtained results.
\end{abstract}

Key words: Mining deformations, Mining tremors.

\section{Introduction}

The impact of an underground mining exploitation on the surface covers many factors (Strzałkowski 2015; Bell et al. 2000). The most often occurring ones in the conditions of Upper Silesian Coal Basin include: continuous deformations, which always accompany the exploitation regardless of geological and mining conditions; non-continuous deformations taking a form of surface deformations (mainly sinkholes) (Strzałkowski 2015) or linear deformations (Strzałkowski and Ścigała 2017). Another possible kind of impact involves rock mass tremors. Several Authors have noticed a relation between the course of mining subsidence (Piwowarski et al. 2017) or subsidence rate (Duda 2016) and seismic activity of the

1 Faculty of Mining and Geology, Silesian University of Technology, Akademicka Street 2, 44-100 Gliwice, Poland. E-mail: piotr.strzalkowski@polsl.pl rock mass. All these forms of impact of mining exploitation on the surface pose a clear danger to buildings. In view of the above, planning an exploitation below a highly urbanised area, as well as analysis of the impact of a finished exploitation on the buildings, must be performed in consideration to individual features of the buildings but also specific mining and geological conditions. Another aspect that needs to be highlighted is a necessity to consider a total impact of different factors on buildings. This problem seems to be quite important, but it does not seem to have been examined well enough until now. Mining induced seismic activity of Upper Silesian Coal Basin has decreased since the 60 s and 70 s of the last century. There are fewer high energy tremors, which is a positive change. However, assessing the impact of these tremors requires individual analyses (Kwiatek 1997).

This paper presents an analysis of the impact of mining exploitation on a building in terms of continuous deformations and rock mass tremors. The conclusions that are expressed in this paper show not only the case of exploitation impact on a selected structure, but also general inferences, suggesting a necessity of individual analysis in each case.

\section{Characteristics of the Building}

The structure was built in 1971, with two storeys, building area of $110 \mathrm{~m}^{2}$ and cubature of $590 \mathrm{~m}^{3}$. The technical condition was estimated as satisfactory, taking into consideration the natural degradation. Based on a point scale, it was estimated that the building is in the fourth category of resistance to static influences (allowed values of deformation 
indices for this category are: inclinations up to $10 \mathrm{~mm} / \mathrm{m}$ and horizontal deformations up to $9 \mathrm{~mm} /$ $\mathrm{m})$, and its dynamic resistance to acceleration of vibration is $1200 \mathrm{~mm} / \mathrm{s}^{2}$ (third category in the GSI scale) (Dubiński and Mutke 2007).

First damage was observed in May 2015. It expanded in Autumn 2015 and manifested as cracks with diagonal, horizontal, and vertical orientation, usually near window frames and doorways in the rooms on all floors. Some of cracks are presented in Figs. 1 and 2.

\section{Analysis of Mining and Geological Conditions}

\subsection{Lithology and Stratigraphy}

The rock mass consists of overburden and carboniferous layers in the area below the building. The overburden consists of tertiary rocks (Miocene) lying under a layer of ground. Based on a profile of a

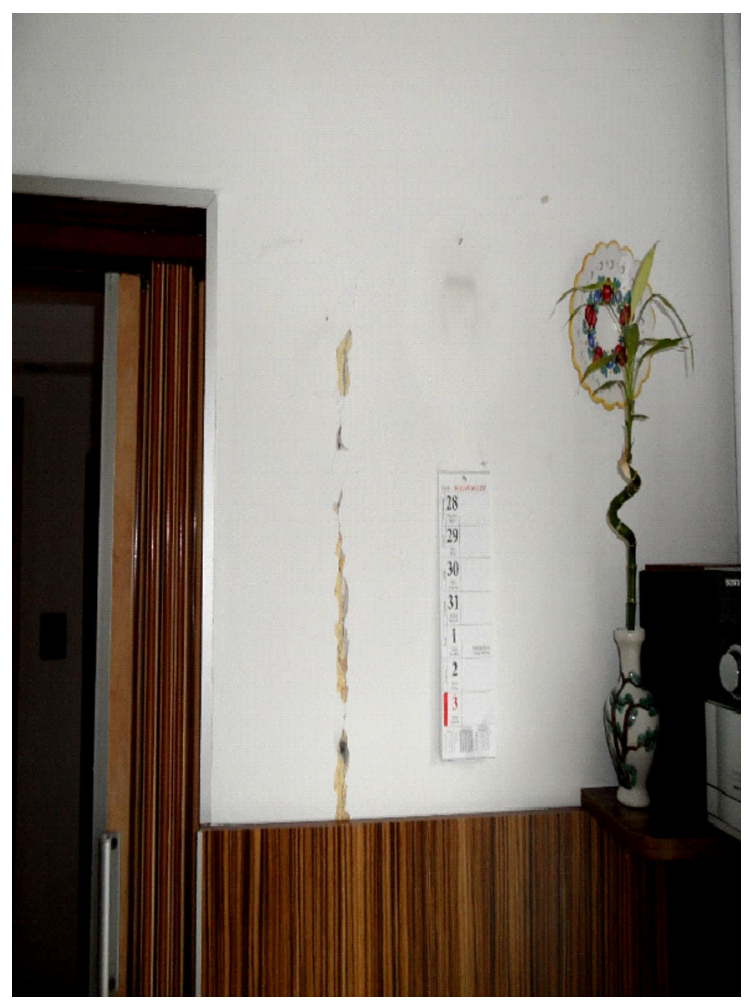

Figure 1

A vertical crack on a wall in the ground floor room

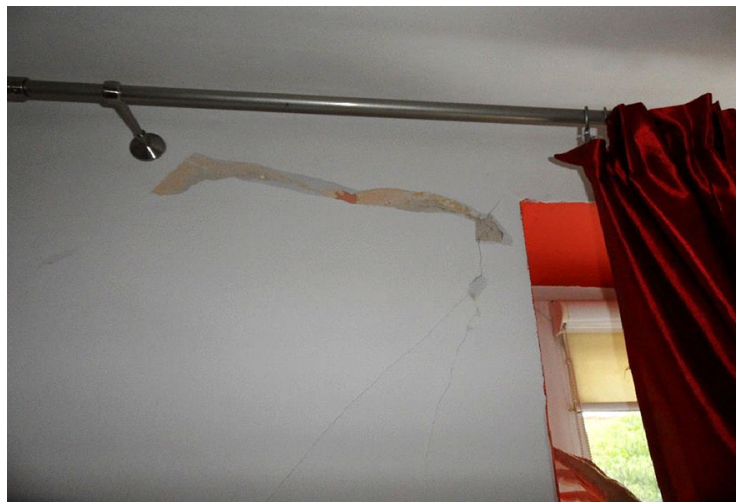

Figure 2

Cracks near the window

drilling hole G112 (Fig. 3), located around $280 \mathrm{~m}$ north-east from the building, it can be assumed that the tertiary rocks lie up to depth of $6 \mathrm{~m}$ and developed in the form of grey-pink loam as well as cream coloured marl and rust-yellow dolomite. Libiąskie layers, which are formed with alternating sandstone layers, shale and coal seams of the group 100 , lie under tertiary rocks. These layers lie up to depth of $190 \mathrm{~m}$. There are łaziskie layers under libiaskie layers, formed in the upper part of the layer which consists mostly of sandstone, and as the depth increases in the form of alternating shale, sandstone, and coal seams of the group 200.

\subsection{Tectonics}

The building is located in a tectonically disturbed area (in the area of fault outcrop on the carbonic roof). The faults of the first group run from northwest to south-east. The second group of faults runs approximately from west to east. (see Fig. 4).

The fault outcrop on the carbonic roof runs near the building. This fault runs from north-west to southeast and the throw slip in the north-eastern direction equals $90 \mathrm{~m}$. The building is placed directly above the fault outcrop running from north-east to southwest. The throw slip in the south-western direction equals $30-50 \mathrm{~m}$. There are other faults in the area below the building, their outcrops are placed further from the building. 


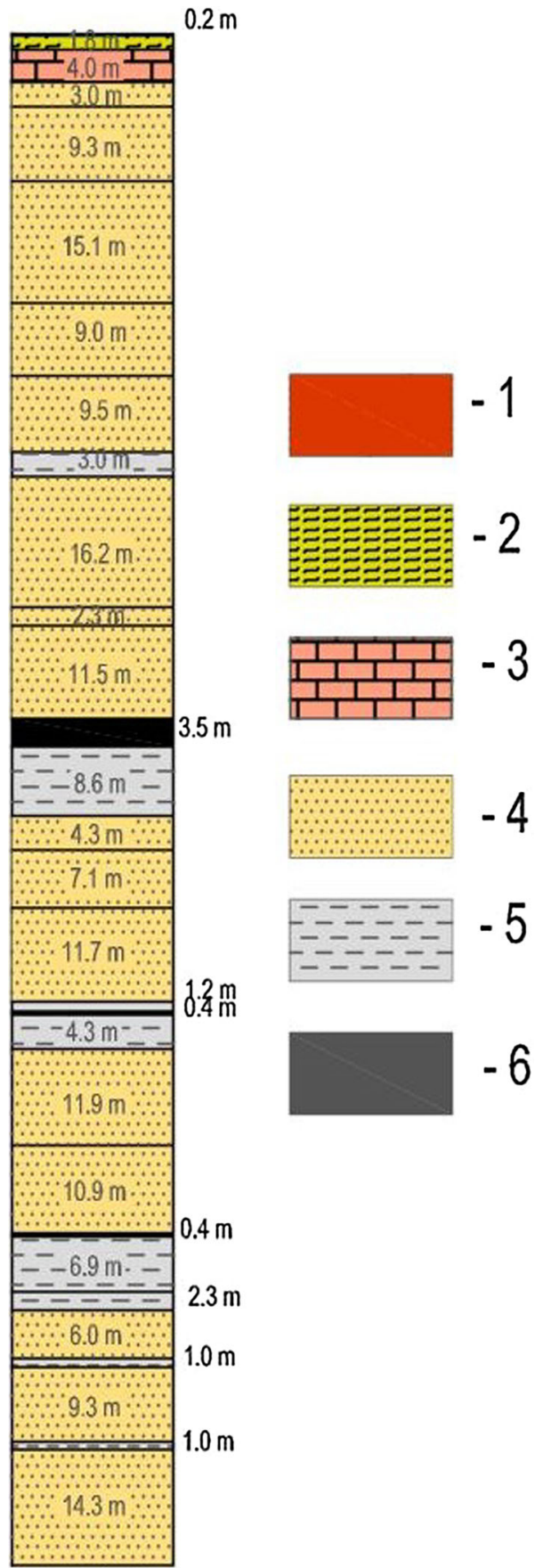

Figure 3

The profile of a drilling hole G112. Markings: 1—soil, 2-graygreen loam, 3-marl, 4-sandstones of different types, 5-slate, 6-coal

\subsection{Mining Operating Conditions in the Area}

The building was affected since 2013 by the exploitation on seam 207 using longwall mining system with coal seam thickness of $3.7 \mathrm{~m}$. The seam lays at an angle between $1^{\circ}$ and $3^{\circ}$. The basic data about this exploitation are presented in Table 1.

Location of longwalls in relation to the building is presented in Fig. 4.

\section{Impact of Mining Exploitation on the Building}

\subsection{Effects of Mining Exploitation Provided by Geodetic Surveys}

The measuring line lies to the west of the building. The nearest control points in relation to the building are points number 9 and 10-see Fig. 4 . They are located around $100 \mathrm{~m}$ from the building. Results of measurements obtained on the control line were selected for further analysis. Figure 4 shows location of the control line in relation to selected longwalls. Measurements had begun in May 2014 and were performed twice a year. Results of the first two surveys show that the deformation (minimal due to the distance) of longwall 1 ended before the first measurement (no increase in values of mining subsidence between first and second measurement). The elevation values of points 9 and 10 in the second measurement on 02.14.2014 were $2 \mathrm{~mm}$ higher than in the measurement from May 2014. While the measurements were carried out, the line was influenced by the exploitation performed by longwalls: 2 , 3 , and 4. Longwall number 5 was too far from the line.

Temporal distributions of mining subsidence of the 9 and 10 control points between 01.05.2014 and 01.03.2017 are presented in Fig. 5. Total subsidence amounted to $43 \mathrm{~mm}$ and $66 \mathrm{~mm}$, respectively. It should be assumed that the subsidence process was not occurring in April of 2017. Just after the last measurements, the benchmarks were damaged but it is assumed no more subsidence has occurred there. 


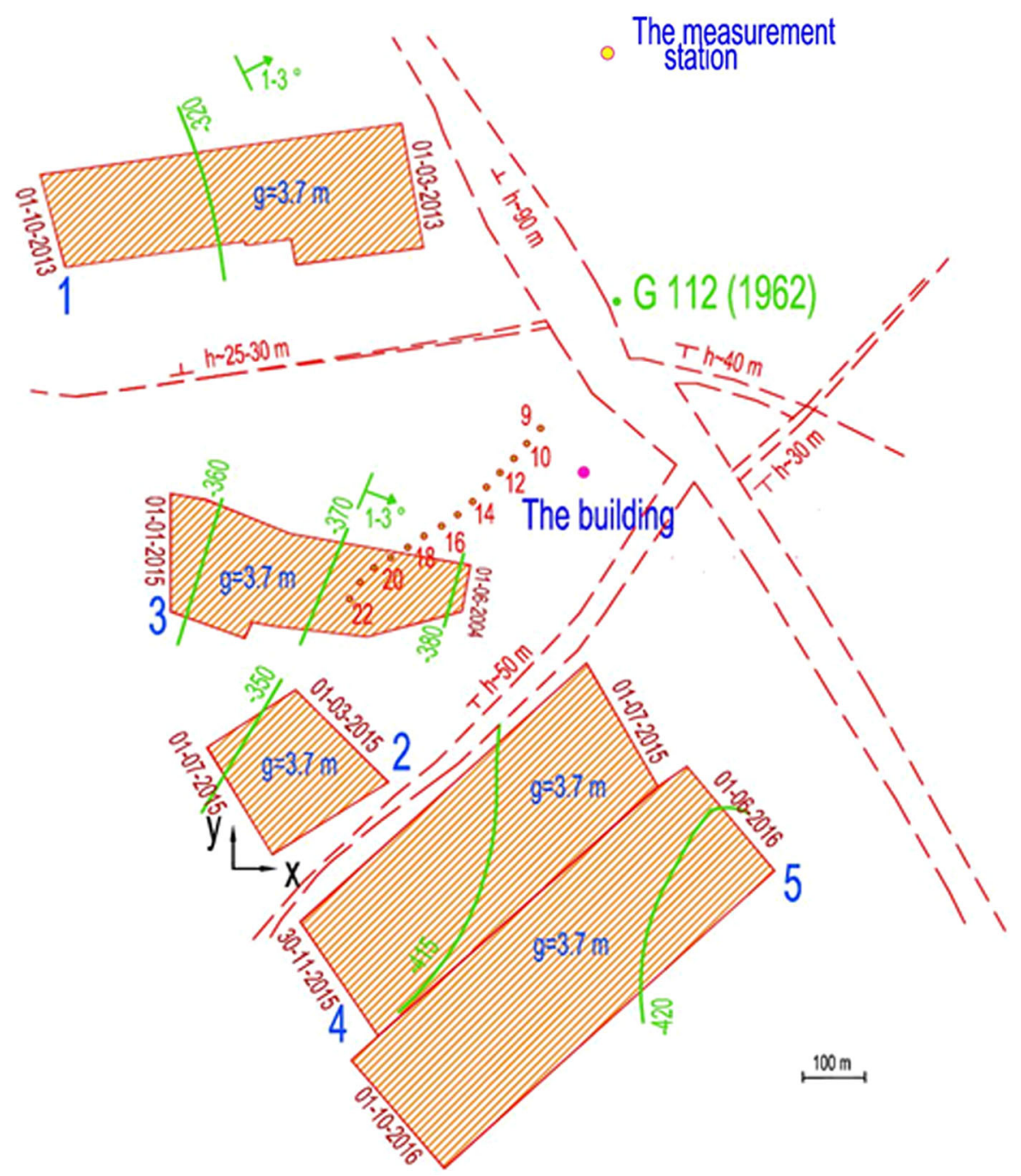

Figure 4

Schematic of localization of extracted panels in coal seam 207 and the building. This also shows the course of faults and location of the measuring line. $\mathrm{X}, \mathrm{Y}$-local coordinate system, Y axis aiming north. Depth isolines near walls presented in $\mathrm{m}$ a.s.l.

Table 1

The basic information about condition of mining exploitation below the building's area

\begin{tabular}{llll}
\hline Panel & $\begin{array}{l}\text { Beginning of extraction } \\
\text { (dd-mm-yyyy) }\end{array}$ & $\begin{array}{l}\text { End of extraction } \\
\text { (dd-mm-yyyy) }\end{array}$ & Depth (m) \\
\hline 1 & $01-03-2013$ & $01-10-2013$ & 572 \\
2 & $01-03-2015$ & $01-07-2015$ & 605 \\
3 & $01-06-2014$ & $01-01-2015$ & 620 \\
4 & $01-07-2015$ & $30-11-2015$ & 665 \\
5 & $01-06-2016$ & $01-10-2016$ & 670 \\
\hline
\end{tabular}

Figure 6 shows mining subsidence over time at points located above longwall 3 where the highest values of the subsidence occurred. Results from June 2017 were selected for further analysis, as their values were insignificantly different.

The mine did not conduct geodetic measurements at points linked to the object itself. Therefore, the results of levelling measurements carried out in its vicinity were used for further analyses. Results of the subsidence measurements allowed to determine the values of the Budryk-Knothe theory parameters discussed below. Subsequently, these parameter 


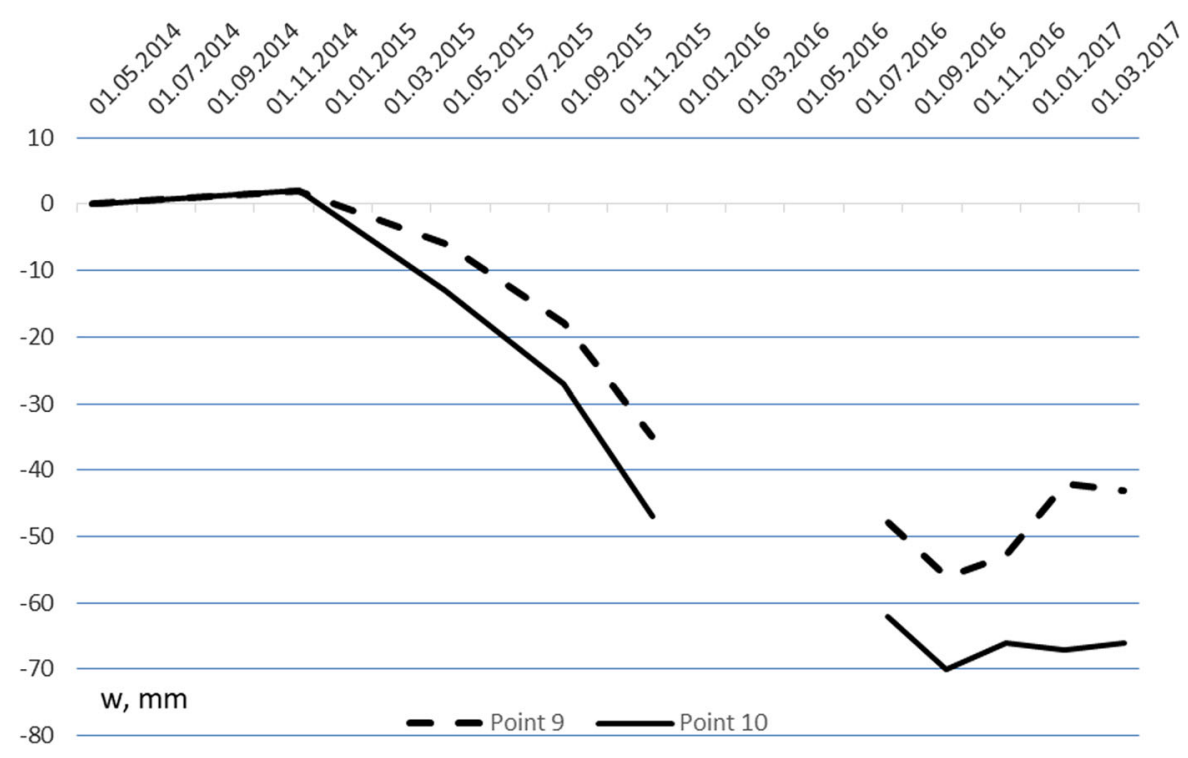

Figure 5

Mining subsidence of control points 9 and 10 between 01-05-2014 and 01-03-2017
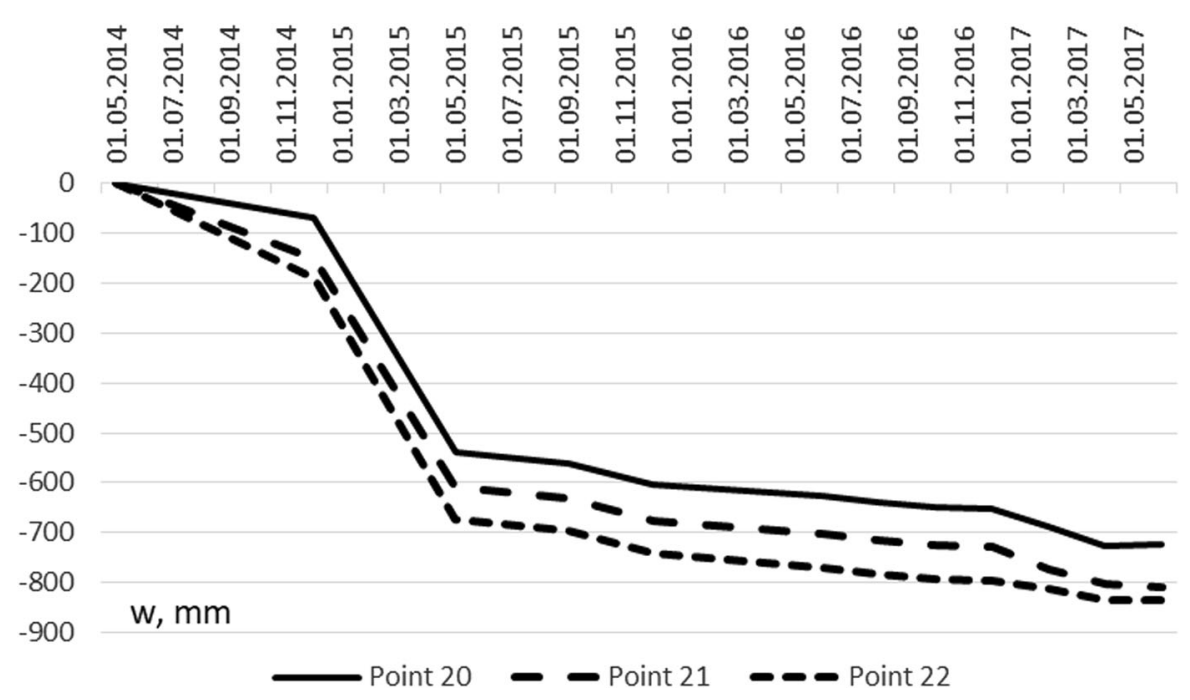

Figure 6

Mining subsidence over time at control points: 20, 21, 22

values were used to calculate: subsidence, slopes, and horizontal deformations at the point linked to the object.

In the Polish mining industry, for the longest time the only theory used for the purposes of predicting the deformation of the mining area was that of $\mathrm{W}$. Budryk-S. Knothe (Knothe 1984; Kratzsch 1983). It allows to achieve error values for subsidence lower than $5 \%$, for slopes and horizontal displacements of 10-20\%, and for curves and deformations of 20-30\% (Strzałkowski 2015; Orwat and Mielimaka 2015).

This theory uses the so-called influence function, similar to other theories known from the literature, like the Ruhrkohle method used in Germany (Ehhardt 
and Sauer 1961). An example of a different type of solution is the Luo and Peng proposition, developed on the basis of a rich database measurement results carried out above the longwall (Luo and Peng 1991). A wide overview of methods used in predicting the deformation of a mining area is presented in the works: (Kratzsch 1983; Whittaker and Redish 1989). In W. Budryk-S. Knothe's theory the final values of subsidence at point $\mathrm{A}(\mathrm{s}, \mathrm{t})$ located on the surface are determined using the equation:

$$
w(s, t)=-\frac{a \cdot g}{r^{2}} \iint_{P} f(x-s, y-t) d P,
$$

where: $f(x-s, y-t)$ - so-called 'influence function':

$$
f(x-s, y-t)=\exp \left\{\frac{-\pi\left[(x-s)^{2}+(y-t)^{2}\right]}{r^{2}}\right\}
$$

$g$ is the coal seam thickness, $a$ is the roof control coefficient, $s, t$ are coordinates of point $A$ in Cartesian coordinate system, $x, y$ are coordinates of elementary extraction field $d P, r$ is the range of main influences, $P$ is the extracted area of coal seam.

The results of parameter values' recognition:

$A$-roof control coefficient,

$\tan \beta$-tangent of an angle of main influences (tan $\beta=\mathrm{H} / \mathrm{r}$, where $\mathrm{H}-\mathrm{depth}$, are presented below:

$$
a=0.54 \tan \beta=1.79 \text { Percentage error : } 3.55 \%
$$

Figure 7 shows subsidence troughs obtained from measurements (points) and calculations (black line and a point). Any disturbance that would suggest an impact of fault on mining subsidence cannot be found in the profile of subsidence through.

The obtained value of roof control coefficient $a=0.54$ is slightly lowered due to small dimensions of the longwalls in relation to radius of the main influences range r. Considering the above, the following parameter values were selected for further calculations.

- Values of roof control coefficient for caving $a=0.7$

- Tangential angle of main influences $\tan \beta=1.8$

- Proportionality coefficient of horizontal displacements to slopes $B=0.32$

- Extraction's periphery $d=0$.

Calculations of the following deformation indices were performed.

- $w$-mining subsidence $(\mathrm{mm})$

- $T_{\max }$-maximal tilt $(\mathrm{mm} / \mathrm{m})$

- $E_{\text {max }}$-maximal deformation $(\mathrm{mm} / \mathrm{m})$

- $K_{\max }-$ maximal curvature $(1 / \mathrm{km})$

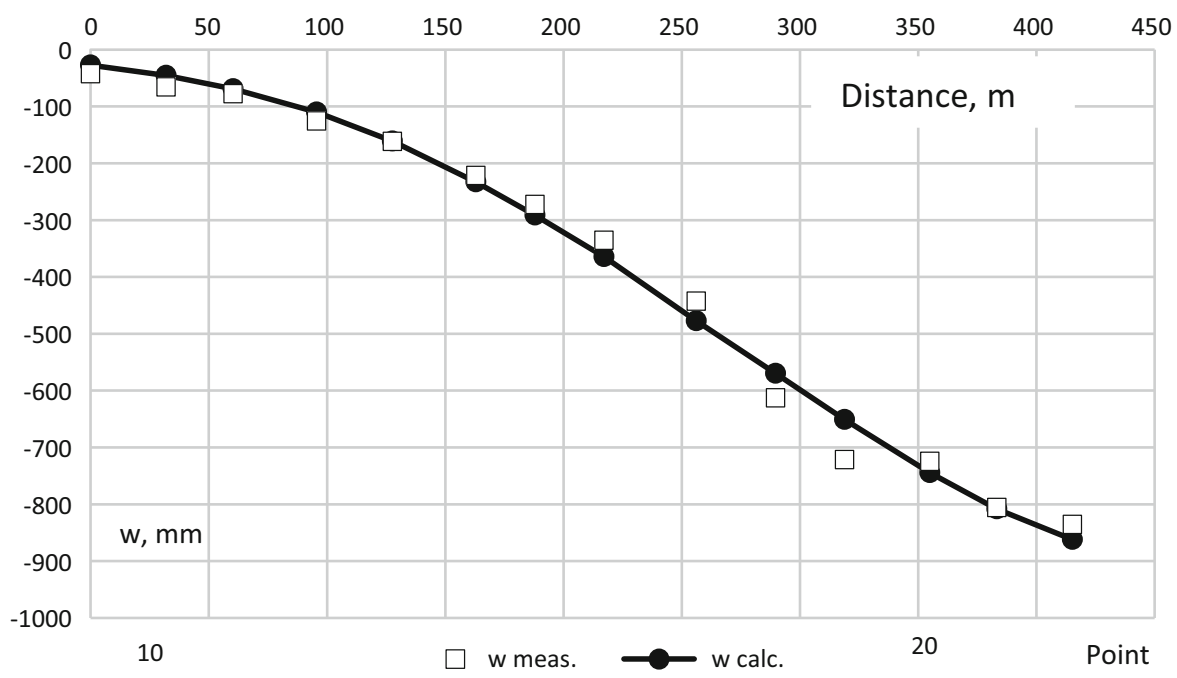

Figure 7

Mining subsidence values obtained from measurements ( $w$ meas.) and calculations ( $w$ calc.) 
Table 2

Values of parameters of deformation evaluated in location of the building

\begin{tabular}{lrllc}
\hline Panel & $\mathrm{w}(\mathrm{mm})$ & $\mathrm{T}_{\max }(\mathrm{mm} / \mathrm{m})$ & $\mathrm{E}_{\max }(\mathrm{mm} / \mathrm{m})$ & $\mathrm{K}_{\max }(1 / \mathrm{km})$ \\
\hline 1 & -0.2 & 0.01 & 0.02 & 0.000 \\
2 & 0.0 & 0.00 & 0.00 & 0.000 \\
3 & -36.2 & 0.59 & 0.88 & -0.008 \\
4 & -11.7 & 0.21 & 0.41 & -0.003 \\
5 & -0.2 & 0.01 & 0.02 & 0.000 \\
Total & -48.3 & 0.75 & 1.05 & -0.009 \\
\hline
\end{tabular}

\subsection{The Impact of Mining Exploitation in Consideration to Calculation Results}

Table 2 presents results of calculations performed using DEFK-Win software of deformations caused by exploitation in the coal seam 207 (Ścigała 2013).

Based on the calculation results the value of subsidence at the point linked to the object was $48 \mathrm{~mm}$. The values of control points 9 and 10 subsidence determined by measurements amounted to 43 and $66 \mathrm{~mm}$. These points were located approximately $100 \mathrm{~m}$ from the object, so it can be concluded that the value obtained as a result of calculations is reliable. Based on the calculation results it can be assumed that the exploitation performed in the coal seam 207 caused deformations from interval of the first category of mining areas in the location of the building. The limit values for category I are: $\mathrm{T}_{\max } \leq 2.5 \mathrm{~mm} / \mathrm{m}$, $\left|\mathrm{E}_{\max }\right| \leq 1.5 \mathrm{~mm} / \mathrm{m}$, $\left|\mathrm{K}_{\max }\right| \leq 0.025 \mathrm{~mm} / \mathrm{m}$. Detailed information about the mining area categories applicable in Poland is presented in paper (Strzałkowski 2015). On the basis of the deformation index values obtained, taking into account the fourth category of the building resistance, it should be therefore stated that continuous deformations could not cause the observed damage.

\section{Impact of Tremors on the Building}

In total 447 tremors of epicentre energies higher or equal to $105 \mathrm{~J}$, were observed in the area of the building from 2014 to July 2017. Figure 8 presents their number in each year, taking the values of energy from particular intervals into account.

These tremors have been observed by the measuring station located $883 \mathrm{~m}$ from the building. Of

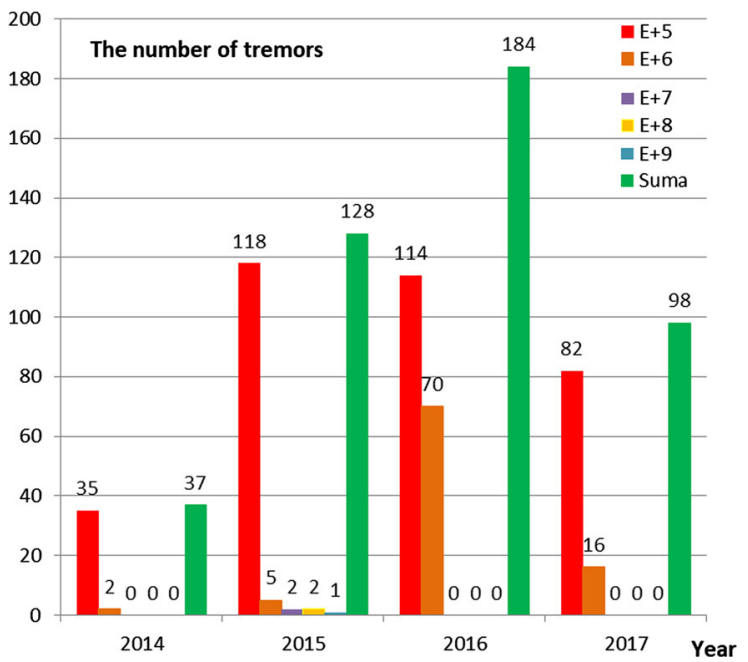

Figure 8

The number of tremors which occurred from 2014 to 2017, taking the values of energy from particular intervals into account

course, accelerations of vibrations in the location of the building were different from values observed by the measuring station due to the distance from the epicentre. Values of acceleration of vibrations can be calculated using G. Mutke's formula (Mutke 1991):

$$
\begin{aligned}
a_{H}= & {\left[1.33 \cdot(\log E)^{2.66}-89\right] \cdot\left[1.53 \cdot R^{0.155}\right.} \\
& \cdot \exp (-0.65 \cdot R)+0.014],
\end{aligned}
$$

where, $a_{H}$ is the horizontal component of acceleration of vibration, $\mathrm{mm} / \mathrm{s}^{2}$ :

$$
R=\sqrt{\mathrm{D}^{2}+0.5^{2}}
$$

$D$ is the epicentre distance, $\mathrm{km} ; E$ is the tremor energy, $\mathrm{J}$.

Values of acceleration of vibrations, calculated this way, concern carboniferous rocks. Rocks of the overburden cause changes in values of accelerations, which is taken into account by multiplying the values obtained from the formula $-a_{H}$ by the so-called amplification coefficient, the value of which depends on the thickness and overburden properties (Lednická and Rušajová 2016; Mutke 1991). First, the calculations were made for the measuring station, to check how the values correlate with the measurement results. Values obtained from the formula were compared with the value $P G A_{H 1 O}$-as seen in Table 3.

It is important to estimate if the formula can be used for calculations performed for the location of the 
Table 3

Parameters of the high energy tremors noted at the measuring station

\begin{tabular}{lllllllll}
\hline $\begin{array}{l}\text { Tremor } \\
\text { symbol }\end{array}$ & Date & Energy $(\mathrm{J})$ & $P G V_{H \max }(\mathrm{m} / \mathrm{s})$ & $t_{H V}(\mathrm{~s})$ & $P G A_{H 10}\left(\mathrm{~m} / \mathrm{s}^{2}\right)$ & $t_{H A}(\mathrm{~s})$ & $D(\mathrm{~km})$ & $\begin{array}{l}P G A_{H 10} \\
\text { Calculated-Eq. (3) }\left(\mathrm{m} / \mathrm{s}^{2}\right)\end{array}$ \\
\hline $\mathrm{A}$ & 18.09 .15 & $2 \mathrm{E}+07$ & 0.0048 & 2.15 & 0.1327 & 1.89 & 1.433 & 0.1411 \\
$\mathrm{~B}$ & 30.09 .15 & $9 \mathrm{E}+08$ & 0.0630 & 1.18 & 1.6350 & 1.04 & 1.484 & 0.2872 \\
$\mathrm{C}$ & 10.10 .15 & $5 \mathrm{E}+07$ & 0.0056 & 2.45 & 0.1029 & 2.52 & 1.486 & 0.1688 \\
$\mathrm{D}$ & 20.10 .15 & $6 \mathrm{E}+08$ & 0.0224 & 3.75 & 0.6614 & 2.55 & 1.468 & 0.2711 \\
$\mathrm{E}$ & 18.11 .15 & $1 \mathrm{E}+09$ & 0.0475 & 2.03 & 1.2082 & 1.39 & 1.603 & 0.2747 \\
\hline
\end{tabular}

$P G V_{H \max }$ h maximal value of resultant amplitude of horizontal vibrations velocity, $t_{H V}$ duration of the intense phase of changes of horizontal vibrations velocity, $P G A_{H 10}$ maximal amplitude of acceleration of horizontal vibrations in frequency band not higher than $10 \mathrm{~Hz}, t_{H A}$ duration of the intense phase of changes of acceleration of horizontal vibration, $D$ distance between the epicentre and the measurement station, km (epicentre of the tremor)

building, especially in case of high energy tremors. Authors suggest (Kwiatek 1997) that there is a need for conducting a separate analysis for high energy tremors. Calculations have been performed for all 447 tremors with a result of compatibility of calculations and measurements for tremors of energy from 105 to $107 \mathrm{~J}$. In case of high energy tremors, calculated values were much lower than those obtained from measurements. Tremors A-E, of energy: $107 \mathrm{~J}, 108 \mathrm{~J}$ and $109 \mathrm{~J}$ were selected for further analysis. Their comparison is presented in Table 3. It also shows values of accelerations, which were calculated on the basis of formula (3), taking into account the amplification coefficient which equals 1.3. Such average value can be used for considered conditions.

Increased values of $P G A_{H 1 O}$ can also be caused by the impact of the fault (Stec and Denysenko 2003; Hofmann and Scheepers 2011). However, analyses of effects of observations do not imply the occurrence of directionality of radiation.

Due to differences of the calculation results obtained from the formula (3) it was decided to perform an analysis of relationship between the horizontal component of vibration acceleration, tremor energy, and epicentre distance in cases of high energy

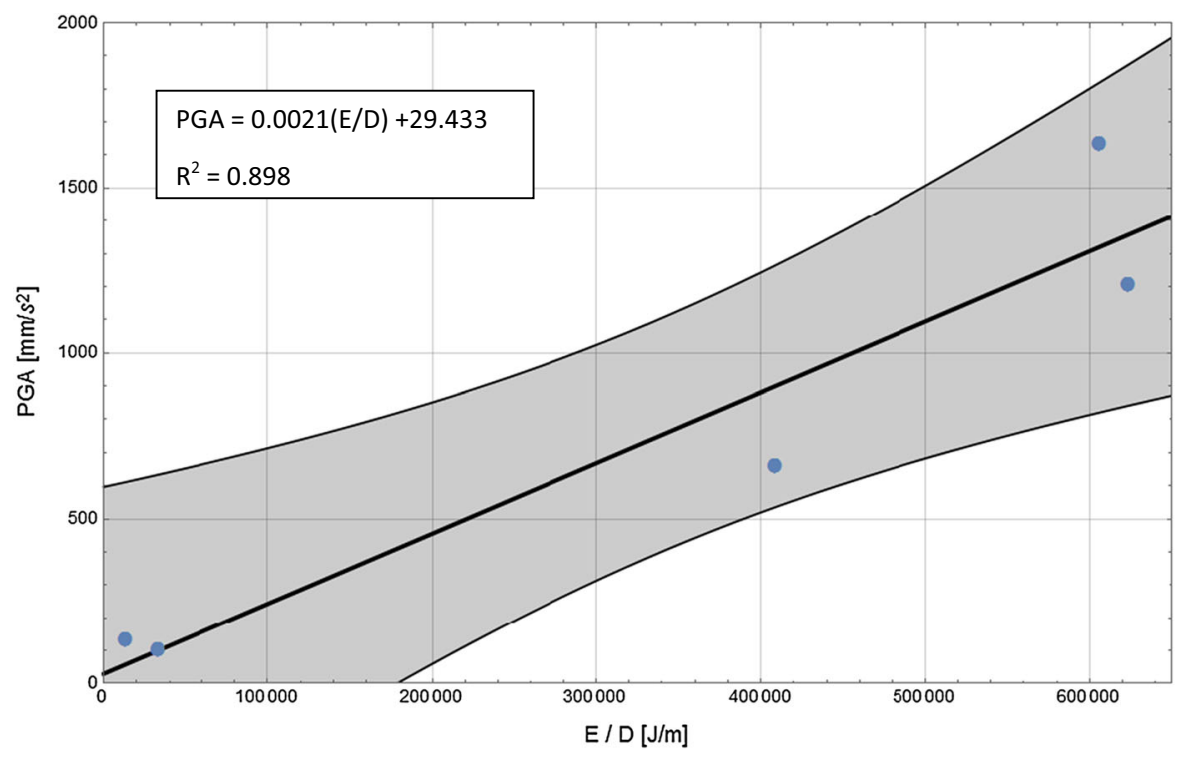

Figure 9

Approximation of the value PGAH10 for high energy tremors (confidence intervals 95\%) 
Table 4

Epicentre distances of tremors of highest energies from the building and calculated values of $P G A_{H 1 O}$

\begin{tabular}{lllll}
\hline Tremor's symbol & Date $(\mathrm{mm}$-dd-yy) & Energy $(\mathrm{J})$ & $D(\mathrm{~km})$ & $P G A_{H 10}\left(\mathrm{~m} / \mathrm{s}^{2}\right)$ \\
\hline A & 09.18 .15 & $2 \mathrm{E}+07$ & 0.533 & 108.2 \\
B & 09.30 .15 & $9 \mathrm{E}+08$ & 0.603 & 3163.8 \\
C & 10.10 .15 & $5 \mathrm{E}+07$ & 0.603 & 203.6 \\
D & 10.20 .15 & $6 \mathrm{E}+08$ & 0.587 & 2175.9 \\
E & 11.18 .15 & $1 \mathrm{E}+09$ & 0.722 & 2938.0 \\
\hline
\end{tabular}

tremors. It is obvious that the acceleration value is proportional to the epicentre energy and inversely proportional to distance. For such a small number of tremors the approximation can only be carried out using the linear function (see equation-Fig. 9), assuming the relation between energy $E$ and epicentre distance $D$ as an independent variable. Of course it is hard to consider this relation (Fig. 9) as an empirical model that could be recommended for mining and geological conditions. However, it provides a perspective on the impact of analysed factors on the value of horizontal component of vibration acceleration. Table 4 presents epicentre distances of high energy tremors and values of $P G A_{H 1 O}$ calculated using the suggested formula in relation to location of the building-Fig. 9.

It needs to be noted that while comparing the distances shown in Tables 3 and 4, the epicentre distances in relation to the building were lower than in the case of measuring station, in all analysed cases. Hence the conclusion that values of acceleration of vibration in the area of the building were also higher than those registered by measurements.

In the case of tremors marked as $\mathrm{B}$ and $\mathrm{E}$, values of $P G A_{H 1 O}$ were much higher than $1600 \mathrm{~mm} / \mathrm{s}^{2}$ and $1200 \mathrm{~mm} / \mathrm{s}^{2}$, respectively. It can be safely concluded that in the case of these two tremors, accelerations which occurred in the area of the building reached values higher than allowed, i.e. values specified by building and construction specialist that should not exceed $1200 \mathrm{~mm} / \mathrm{s}^{2}$. Moreover, it must be said that occurrence of the fault zone could have been a cause of the increase of the vibration acceleration value. According to the formula shown in Fig. 9, $P G A_{H 1 O}$ have even reached approximately $3000 \mathrm{~mm} / \mathrm{s}^{2}$.

To assess the impact of tremors on buildings in Upper Silesian Coal Basin, application of the GSIGZWKW2012 scale is recommended (Mutke 2012). The scale takes into account the diversity of buildings due to type of construction, their technical conditions, and their heights not exceeding 12 floors, which are located in the area of Upper Silesian Coal Basin. Two parameters are used to assess the impact of tremors.

- $P G V_{\text {Hmax }}$-maximal value of resultant amplitude of horizontal vibrations velocity.

- $t_{H V}$-duration of the intense phase of changes of horizontal vibrations velocity.

The scale distinguishes five stages of intensityfrom 0 to IV. Impact of mining tremors on buildings and linear objects of underground infrastructure as well as intensity of vibration sensed by people and nuisance of usage of buildings were all described for these stages. The intensity of vibration is specified based on an appropriate diagram.

Intensity of vibrations caused by tremors of highest accelerations can be specified in the area of measurement station using the data from Table 3 (taking $P G V_{\text {Hmax }}$ into account), as it is presented below.

- For tremor A extent 0 (tremors almost unnoticeable, no damage).

- For tremor B extent IV (tremors can cause damage to the building).

- For tremor C extent I (tremors almost unnoticeable, no damage).

- For tremor D extent II (tremors intensifying previous damage).

- For tremor E extent IV (tremors can cause damage to the building).

\section{Summary and Conclusions}

The paper presents data concerning the problem of deformations caused by mining as well as an 
individual example of a building affected by tremors, and discusses its subsidence. In the opinion of the author this kind of analysis should be performed with consideration of the following rules.

1. Calculations of deformation indicator values should be verified by geodetic surveys. Unfortunately, currently they are hardly ever carried out, especially in the case of single buildings. Values of parameters adopted for calculations should be, as much as possible, verified by geodetic surveys performed in the area of the building. This allows to obtain reliable results of calculations of basic deformation indicators, which are necessary for assessing the impact of exploitation on a specific building. The values of parameters of S. Knothe's theory were defined based on the results of measurements performed on a control line located relatively close to the building (around $100 \mathrm{~m}$ ), what makes the results of calculations of deformation indicators in the area of the building very reliable.

2. The empirical formula used to express acceleration of vibrations in the function of energy and epicentre distances is compatible with the results of measurements for the most commonly occurring tremors, i.e. ones with energy of $107 \mathrm{~J}$ or lower. Tremors of higher energies rarely occur, hence the difficulties in finding statistical results of measurements. In view of the above, analysis of influence of high energy tremors of the rock mass on a specific object should be supported by results of surveys of vibration accelerations and demands separate analysis. Usually, the results of measurements carried out in the area of the considered building are available. In the considered case, the increased values of $P G A_{H 1 O}$ could also have been caused by the impact of the fault.

3. Distances between the epicentre of all tremors and the measuring station were greater than the distances between the epicentre and the building. Having the results of vibration accelerations surveys, caused by higher number of high energy tremors, the empirical formula for specific geological conditions can be worked out. In the case analysed in this paper, basing calculations only on the formula (3) would result in obtaining incorrect values of acceleration of vibration horizontal component, which would lead to incorrect conclusions.

4. In the light of presented analysis, it must be concluded that continuous deformations were not the cause of damage to the object. It was a result of the rock mass tremors, producing accelerations with values exceeding the limits for the object in question. These tremors would cause damage to the building even if not occurring alongside continuous deformations. The measurements results indicate the necessity of individual analyses of high energy tremors in specific geological and mining conditions.

5. Determining all forms of mining exploitation impact on a building in a reliable manner constitutes a basis for further analysis by experts in the area of civil engineering in mining areas.

Open Access This article is distributed under the terms of the Creative Commons Attribution 4.0 International License (http://creativecommons.org/licenses/by/4.0/), which permits unrestricted use, distribution, and reproduction in any medium, provided you give appropriate credit to the original author(s) and the source, provide a link to the Creative Commons license, and indicate if changes were made.

Publisher's Note Springer Nature remains neutral with regard to jurisdictional claims in published maps and institutional affiliations" (in PDF at the end of the article below the references

\section{References}

Bell, F. G., Stacey, T. R., \& Genske, D. D. (2000). Mining subsidence and its effect on the environment: some differing examples. Environmental Geology,40(1-2), 135-152. https://doi. org/10.1007/so0025400001.

Dubiński, J., \& Mutke, G. (2007). Mining GSI-GZW Intensity Scale to assess the effects of mining tremors in the Upper Silesian Coal Basin on buildings and people. In Scientific works of GIG, mining and environment, Special Edition (pp 199-211). Katowice: GIG Quarterly (in Polish).

Duda, J. (2016). Relation between benchmark displacement velocity and seismic activity caused by underground longwall. Acta Geodynamics Geomaterialia,51(4), 709-722. https://doi. org/10.1007/s40328-015-0154-0. 
Ehhardt, W., \& Sauer, A. (1961). Die Vorausberechnung von Senkung. Schieflage und Krümmung über dem Abbau in flacher Lagerung. Bergbauwissenschften, 8, 415-428.

Hofmann, G. F., \& Scheepers, L. J. (2011). Simulating fault slip areas of mining induced seismic tremors using static boundary element numerical modelling. Journal Mining Technology, 120(1), 53-64. https://doi.org/10.1179/037178411X12942393517291.

Knothe, S. (1984). Forecasting the Impact of Mining Exploitations. Katowice: 'Śląsk' Publishing House (in Polish).

Kratzsch, H. (1983). Mining Subsidence Engineering. Berlin: Springer-Verlag.

Kwiatek, J. (1997). Building facilities in mining areas. Katowice: Publishing House of GIG. (in Polish).

Lednická, M., \& Rušajová, J. (2016). Experimental measurement at the seismic station Ostrava-Krásné Pole (OKC): Preliminary results and remarks on site effect at the studied locality. Acta Geodynamica et Geromaterialia, 13(2), 137-147. https://doi.org/ 10.13168/AGG.2015.0051.

Luo, Y., \& Peng, S. S. (1991). Some new findings from surface subsidence monitoring over longwall panels. International Journal of Mining Engineering,43, 1261-1284.

Mutke, G. (1991). The method of predicting vibrations parameters of the ground generated by mining tremors in Upper Silesian Coal Basin conditions. Doctoral dissertation unpublished. GIG Katowice (in Polish).

Mutke, G. (2012). Mining GSI-GZW Intensity Scale website GIG. https://www.grss.gig.eu.
Orwat, J., \& Mielimąka, R. (2015). The comparison of measured deformation indicators of mining area with theoretical values calculated using Knothe's formulas. International conference of numerical analysis and applied mathematics. https://doi.org/10. 1063/1.4951849.

Piwowarski, W., Strzałkowski, P., \& Ścigała, R. (2017). Analysis of rock mass destruction processes with different activity diagrams. Acta Geodynamica et Geromaterialia,13(1), 83-92. https://doi.org/10.13168/AGG.2016.0030.

Stec, K., \& Denysenko, S. (2003). Characteristics of tremors of the rock mass observed in the Kłodnicki fault zone-KatowicePanewniki. Workshop 2003 from series 'Natural dangers in mining', pp. 269-279 (in Polish).

Strzałkowski, P. (2015). Outline of protection of mining areas. Gliwice (in Polish): Publisher of the Silesian Technical University.

Strzałkowski, P., \& Ścigała, R. (2017). The causes of mining induced ground steps occurrence-Case study from Upper Silesia in Poland. Acta Geodynamica et Geromaterialia,14(3), 305-312. https://doi.org/10.13168/AGG.2017.0013.

Ścigała, R. (2013). The identification of parameters of theories used for prognoses of post mining deformations by means of present software. Archives of Mining Sciences,58(4), 1347-1357. https:// doi.org/10.2478/amsc-2013-0093.

Whittaker, B. W., \& Redish, D. J. (1989). Subsidence-Occurrence, prediction and control. Amsterdam: Elsevier. 